\title{
BENEFITS AND CHALLENGES OF THE ADOPTION OF CLOUD COMPUTING IN BUSINESS
}

\author{
Colin Ting Si Xue ${ }^{1}$, Felicia Tiong Wee Xin ${ }^{2}$ \\ ${ }^{1}$ School of Computing and Technology \\ Asia Pacific University of Technology and Innovation \\ Technology Park Malaysia \\ 57000 Kuala Lumpur, Malaysia. \\ ${ }^{2}$ Department of Health Science \\ International Medical University \\ No. 126, Jalan Jalil Perkasa 19, Bukit Jalil \\ 57000 Kuala Lumpur, Malaysia.
}

\begin{abstract}
The loss of business and downturn of economics almost occur every day. Thus technology is needed in every organization. Cloud computing has played a major role in solving the inefficiencies problem in organizations and increase the growth of business thus help the organizations to stay competitive. It is required to improve and automate the traditional ways of doing business. Cloud computing has been considered as an innovative way to improve business. Overall, cloud computing enables the organizations to manage their business efficiently. Unnecessary procedural, administrative, hardware and software costs in organizations expenses are avoided using cloud computing. Although cloud computing can provide advantages but it does not mean that there are no drawbacks. Security has become the major concern in cloud and cloud attacks too. Business organizations need to be alert against the attacks to their cloud storage. Benefits and drawbacks of cloud computing in business will be explored in this paper. Some solutions also provided in this paper to overcome the drawbacks. The method has been used is secondary research, that is collecting data from published journal papers and conference papers.
\end{abstract}

\section{KEYWORDS}

Benefits, Challenges, Cloud Computing, Deployment Models, Service Models.

\section{INTRODUCTION}

Cloud Computing is quickly becoming one of the most popular and promising technologies. It offers variety of opportunities that help the organizations to improve their business and use technology more efficiently. Many organizations have started adopting cloud computing in their business. It is difficult for the organizations to survive in the traditional ways and they are unable to compete with their competitors. Especially in this competitive environment, respond quickly to business demands is necessary. The organizations are necessary to implement strategic ideas to gain competitive advantages. Cloud computing is an enhanced technology and become a vital technology to run business. It acts as an excellent technological tool that helps the organizations to stay competitive as it can be considered as an innovative way to increase business value. It enables the users and consumers to integrate and combine many different services together that increases the creativity and productivity. Cloud computing has successfully gained the interested from organizations because it offers a wide range of solutions and advantages to business such as 
increase flexibility, scalability, agility, reduces costs and higher efficiencies [20,36,64]. Thus more and more organizations start migrating their services and applications to cloud. Cloud computing has been used and applied in organizations and it helps to gain revenue every year [1,38]. Cloud services market revenues are expected to reach at 66 billion dollars in 2016 and its growing rate will be around $30 \%$ per annual [7,94]. The fast growing rate of cloud computing is unavoidable. As the technology is getting more advanced, cloud computing raises some concerns in security, cloud attacks and privacy. The organizations should have proper protection on cloud services to prevent their data being stolen. The objectives of this paper are to explore the benefits of cloud computing, identify the threats to cloud computing and determine the solutions to overcome threats in business.

At the beginning of this paper, it gives an overview of cloud computing. It discusses different types of definitions from different experts on cloud computing. Besides, the cloud computing service models and deployment will be provided to show the characteristics of different models. The reasons and challenges of the adoption of cloud computing in business will be analysed. Suggested solutions to overcome the challenges will be provided. Finally, future research has been included in the conclusion.

\section{Cloud Overview}

There are some debates on the definition of cloud computing. Confusing problem like the lack of agreed-upon definitions, always appeared in the cloud, as different experts provide different definitions. Different types of services will be provided by cloud computing to the subscribers through the Internet. Cloud computing is something that all applications and services moved into "cloud". The word "cloud" can be defined as remote environment from Information Technology perspective [55]. However, [7] defined cloud as a large pool where computing resources are stored. Usually, it provides a single, simple interface for the users to use and hide the architecture. Figure 1 illustrates the architecture of cloud computing.

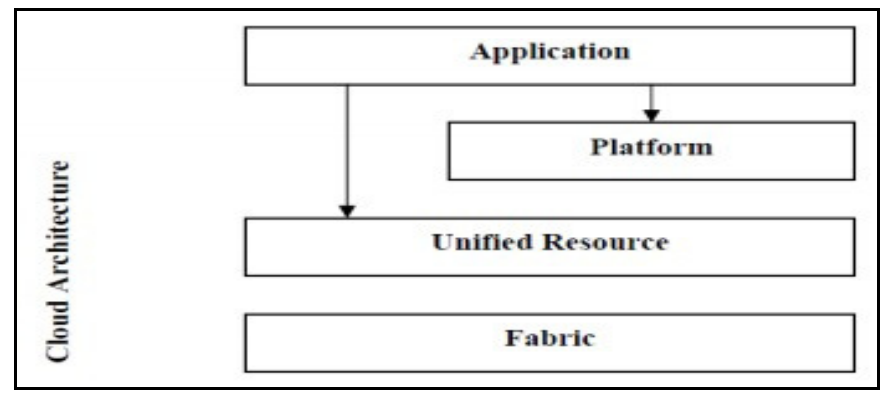

Figure 1. Cloud Computing Architecture [7].

In cloud computing architecture, there are four main layers. The first layer, fabric, contains all physical, computational devices and hardware resources such as network bandwidths, computing units, storage system etc. [35]. The second layer, unified resource, contains virtualized resources which act as integrated resources. The physical machines have been encapsulated in order to act as integrated resources for the end users [63]. In third layer, which is the platform layer, contains new resources such as specialized tools, middleware and services. The main purpose of this layer is to reduce the burden of deploying applications directly into virtual machine container [96]. The development environment is provided for the developers to develop applications. Finally, the top layer, application, contains the applications that run and execute in the cloud [35]. According to [1], the users can use cloud services provided by cloud providers without having any operational 
knowledge. The users do not need any special requirements or devices to access these services. The services provided by cloud are 24/7. Sometimes, it can also be used to trace when the computing resources and applications are used. [30] found that cloud computing is able to provide shared resources, applications and services that meet changing business needs. Cloud computing also provides a platform that enables the developers to develop and deploy directly to the cloud. They do not need to worry about how many resources they need, system maintenance and upgrade as these are done by the providers.

\subsection{Cloud Computing Service Models}

Cloud computing providers offer different types of services to their users based on the main three types of service models. Figure 2 shows the three main types of service models in cloud computing.

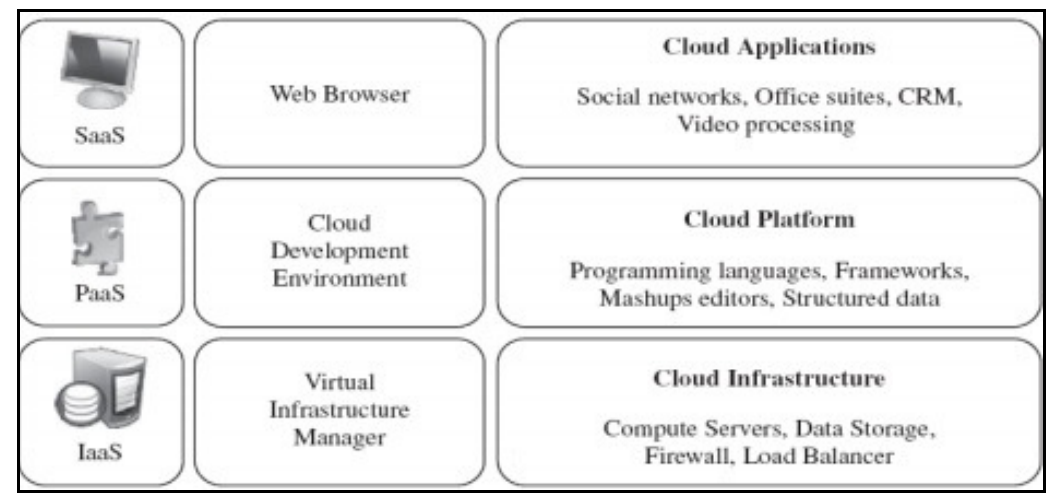

Figure 2: Cloud Computing Service Model [34].

\subsubsection{Service as a Service (SaaS)}

Service providers will install their software applications which operated by them for the users to use as a service. The users can rent it on a subscription or pay-per use model [17]. The users can access the software applications without the concerns of installation and maintenance. They also do not need to know the infrastructure and platform where the applications are running [43,51]. Compared to the traditional software, SaaS does not require own software and hardware resources. SaaS is popular due to its scalability, compatibility, accessible worldwide and the users do not need to do/worry about scaling, configuration and updates [51]. However, users do not have any control on the components, security and application customization [58]. Examples of SaaS are Google Docs, Microsoft Office 365, salesforce.com etc. [96].

\subsubsection{Platform as a Service (PaaS)}

PaaS plays a major role in cloud as development environment will be provided by service providers for application developers to implement and maintain their applications [27]. A platform, including software, hardware, operating system, server, development tool and database will be provided by service providers [17]. Users do not need to know how much processing unit, memory, storage they need for their applications. PaaS provides a full "Software Lifecycle" since it allows the application developers to directly implement on the cloud. The difference between $\mathrm{PaaS}$ and $\mathrm{SaaS}$ is the users to develop the applications on cloud or host the completed applications on PaaS while the users can only host the completed applications on SaaS [68]. Some examples of PaaS are Amazon Web Services, Google App Engine and Microsoft Azure [5]. 


\subsubsection{Infrastructure as a Service (IaaS)}

The bottom layer of service model is IaaS. The main concept of IaaS is virtualization. IaaS provides the infrastructure for the applications to run. IaaS provides the necessary computational resources and infrastructure such as storage, processing unit, networks etc. [42]. [51] said that IaaS is like located in the middle of the other two services as it acts as a physical or a virtual machine to support users' applications. It allows users to deploy and run both operating systems and applications. The main benefit is that users do not take any responsibility on deployment, administration and maintenance [11]. An example of IaaS is Amazon EC2 [37].

\subsection{Deployment Models}

Cloud computing has been classified as four types of deployment models: public cloud, private cloud, community cloud and hybrid cloud [87]. Each of the model has its own scope of services offered to the users. The ways of Cloud Computing deployment will be based on different factors, such as customization capabilities, cloud services sharing, security requirements and location the services hosted [90]. Figure 3 shows the different types of cloud deployment models.

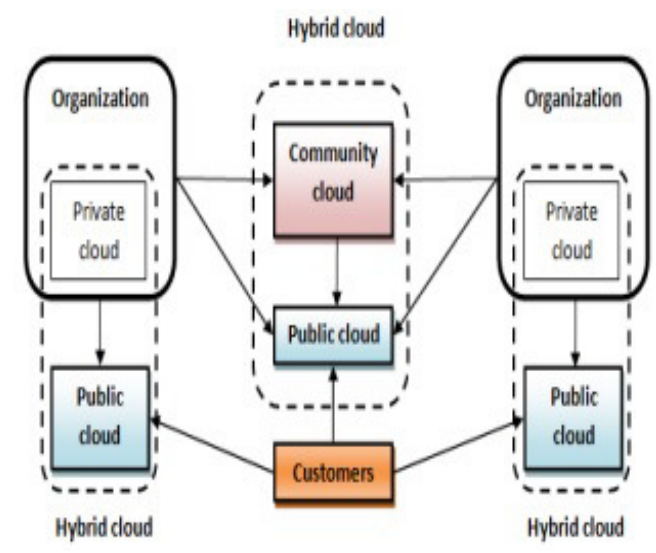

Figure 3. Cloud Deployment Models [4].

In public cloud, the services are offered to everyone in general public over Internet. These services are provided and shared with other organizations by third party service providers. Usually the service providers have their own policy, value, costing and charging model. [90] found that the services delivered are manageable and consistent available. However, the users are treated as untrustworthy. Researchers found that privacy and security are the issues that always discussed in public cloud [3,4]. Examples of public cloud services are email services and photo storage services.

Private cloud service is for organization usage. Compared to public cloud, private cloud has a higher security because it is only accessible by the trusted users in the organization or granted third parties. An example of using private cloud in an organization is to share customer data to their other branches [81]. This type of cloud service is less risky, higher security, higher energy efficiency, more reliable, cost reduction and lower complexity $[32,96]$. Research has been done to prove this by putting an organization in the most precarious situation [60]. However, an organization needs to spend more cost on purchasing the software and equipment to have their own cloud. 
Community cloud located between public and private cloud. There are not much different from private cloud. The resources are shared among the organizations that have similar missions and requirements [25]. The services may be managed by third parties or organization itself. According to [81], the setup cost is cheaper than a private cloud because they are shared among the organizations. Besides, it offers a higher level of security and privacy. One of the drawbacks is the data storage needs to be shared among others. An example of community cloud service is the educational cloud that can be shared among the universities around the world for research purpose [4].

Hybrid cloud is the composition of two or more clouds, either public, private or community [75]. The clouds will use the physical hardware and server instances together to provide a service. This type of cloud service offers the same advantages of public and private cloud. In hybrid cloud, it is easier to handle data security concerns by saving the organizations' sensitive data in private storage. Usually this type of cloud service is used for backup purpose [83]. The organization can host a critical application on private cloud and public cloud for less security concern [31].

\section{Benefits Of Cloud CoMputing In BuSiness}

Cloud computing tends to be different from the other computing concepts. Basically, it supports an interactive and user friendly web applications. Different people will have their own perspective. Some people will consider cloud computing as a virtualized computer resources, dynamic development and software deployment. In today's world, cloud computing has played an important role especially in business. [66] found that cloud computing as an innovative technology helps the organization to stay competitive among others. It is able to bring a various benefit to business. Cloud computing is able to provide improved new capabilities which the traditional IT solution cannot provide.

\subsection{Flexibility}

Most of the organizations choose to adopt cloud computing as it increases the business flexibility. It allows every employee to be more flexible in or out of their workplace. Employees who are on business trip can access the data as long as they have Internet connection through any kind of device $[18,54]$. Various services provided by cloud computing help the organizations handle the business demand. Cloud computing allows the employees to share documents and files over the Internet simultaneously. Thus, every employee can get the updated version. This gives an added advantage especially for an organization's employees who often work outside of the organization and now they can easily access to their data [44]. Thus the business owners do not need to be in one location, but now can spend their time on other business in another location. Besides, due to the data and files are stored virtually on the Internet, it allows the employees to access the same resources simultaneously.

\subsection{Cost Reduction}

According to [66] and [88], the main reason that organizations adopting cloud computing in their business is it helps in cost reduction. Organizations are enamoured by the chance of cost reduction as the cloud service providers provide "in-house" provision of these services [22,23]. Besides, the organizations pay only for what they use. It means the organizations only pay for the services that they use when they access cloud services. Figure 4 shows the reasons of the organization to adopt cloud computing. 


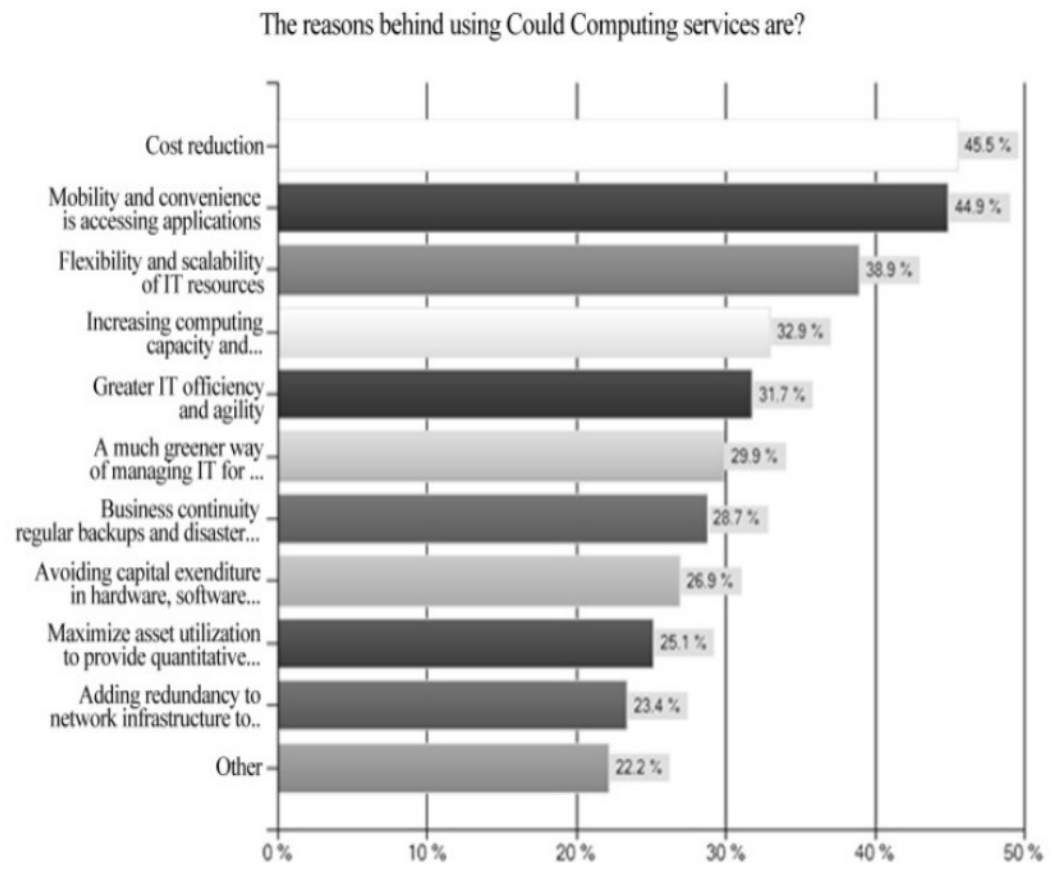

Figure 4: Reasons for Adopting Cloud Computing [66].

The main reason that motivates the organization to adopt cloud computing is cost reduction which is $45.5 \%$. [12] and [76] stated that cloud computing has helped the organizations to save a huge cost mainly due to its subscription models. The resources on cloud computing can be installed and deployed very quickly, especially SaaS, due to everything is done by the providers [71]. Usually these services are managed, patched and upgraded by the providers. When the responsibilities of maintaining these services have been transferred to the providers, the organizations do not need to worry about the IT problems. Besides, the technical support is usually done by the providers and thus reduces the burden on IT staffs [14]. This can help the organizations to prevent any staff training cost and manpower.

\subsection{Automatic Software/Hardware Upgrades}

According to [61], when an IT solution has been implemented in organizations, it creates a problem that is unable to have an appropriate financing due to the high cost of purchasing and maintaining hardware and software. This will give a negative effect. These problems can be solved by adopting cloud computing. The organizations can shift their capital expenses to operating expenses. It does not only reduce the cost, but it helps to build a better relationship, remain in technological advances, increase the profit, provide standardized and low cost services to customers [1]. This encourages more organizations willing to purchase Supply Chain Management and Customer Relationship Management applications because of economical subscription fees. The employees are able to access to these applications immediately. Due to there is no any capital investments for immediate access, it results in a faster time to the market. Besides, cost reduction in these will also lower the entry barrier [28,29]. This will increase the opportunities and encourage more organizations, especially in far behind IT revolution countries to start their business. 


\subsection{Agility}

In today, such a highly competitive business environment, it is necessary to stay competitive. [36] highlighted that one of the ways to make organization different from others is the ability and time used to respond to customers' fast changing needs. [84] stated that cloud computing can achieve this in a more effective manner. Due to the availability of the Internet, cloud computing is around the clock. This helps the organizations to deliver the services in shortest time, thus it can be used as a competitive tool for rapid development [71].

Cloud computing increases agility by offering three types of low-level administrations from cloud providers [16]:

- System Infrastructure - machines and spare part maintenances

- Backup Policy - backup management

- Single Application - software management (upgrade software / application support)

Cloud computing helps to increase the agility that is able to adapt quickly to respond the changes in a business environment. Compared to the cloud server, it will just take a minute to procure and provision while a normal physical server will take days.

\subsection{Scalability}

Another benefit of cloud computing is it allows the users to adjust the resources based on the changes of business needs. This can be done by expanding the computing infrastructure as most of the cloud computing interface is user-friendly [21]. [10] said the traditional IT solutions do not support scalability and it brings lots of inconvenience to the organizations. The organizations are refusing to maintain the resources during the peak time because they are not being used in normal time. This might cause the loss of customers due to their dissatisfaction. Due to the scalability of services in the cloud, it helps to solve the problems and increase customer satisfaction. Cloud computing is able to make the resources available quickly, which removes the capacity planning needs. Cloud computing is an added advantage especially for smaller organizations because they can expand the resources when necessary [52]. Besides, cloud computing allows the users to analyse a huge amount of data in just a few minutes due to its processing power [24]. This has successfully attracted the business analysts to analyse market and predict the customers' behaviour and buying habits.

\section{Risks OF ClOUd COMPUTING In BUSINESS}

Cloud computing, which some people claimed as a new technology, has helped a lot of organizations in doing business. Although cloud computing brings some benefits to the organizations as aforementioned, there are some shortcomings for decision makers that need to be taken into consideration [6]. Cloud network traffic will be pernicious to the performance of cloud. When cloud capacity is more than $80 \%$ occupied, the computers will be irresponsible [77]. There is the chance of crashing between servers and computers. This will lead to the loss of valuable data such as customers' data, organizations' sales report etc. Cloud attack is also a major issue in cloud computing. Cloud computing is a place for the users to host their web services such as web hosting and cloud storage. This has attracted the hackers to steal the business data, such as daily sales, profit reports, financial reports etc. [33]. [69] highlighted the types of cloud attacks such as malware injection attack, wrapping attack, SQL injection, authentication attack and Denial of Service. 


\subsection{Data Stealing}

The number of users and organizations connected to the Internet is increasing. This also increases the probability of probing and attacking using viruses, worms and cyber terrorists. An incident has happened in one of the service providers, Google Inc., which their servers have been hacked [13]. Figure 5 illustrates the percentage of key concerns issues in cloud computing.

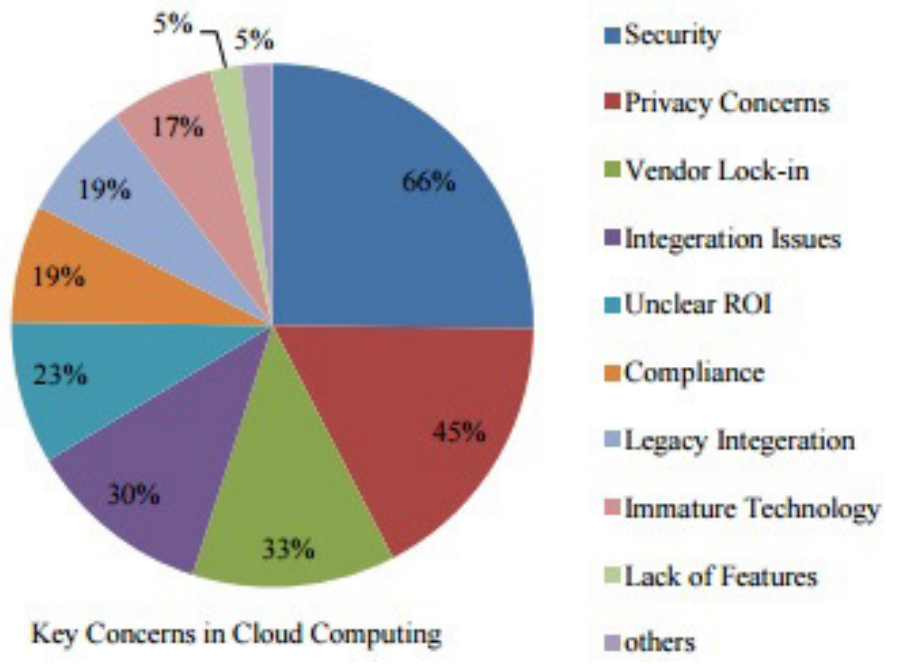

Figure 5: Cloud Computing Adoption Issues [56].

Among the issues of adopting cloud computing in business, security occupied the highest percentage that is $66 \%$. A survey conducted by International Data Corporation (IDC) shows that security is the primary challenge [47]. The reason is there is the involvement of third parties to provide services. [50] also stated that security is the most concern threat and this has brought the pressure to cloud service providers in order to provide a better protection for their clients' stored data. The security issue includes networks, operating system, databases, transaction management etc. Data stealing has become a major issue in cloud computing. Some of the service providers do not have their own server, they acquire the services from the other providers since they are more cost effective and flexible for operation. This increases the chances of data stolen from external servers [2]. As cloud computing has provided powerful processing capabilities and huge amount of storage for the users or organizations, this encourages organizations to move to cloud so they do not need to spend money on purchasing servers. According to [86] report, around $37 \%$ of global companies involved in a malicious attack. One of the companies, Zappos, became a target for cyber theft. There are around 24 million of their users' account details being stolen such as their personal information, credit card information and also encrypted password [86].

\subsection{Malware Injection Attack}

The hackers will try to damage the applications and websites hosted on the cloud. Usually hackers will find the vulnerabilities of a web application or website and make some changes to it thus change the normal execution. Hackers will program a malicious application and use the virtual machine to inject the malware into the cloud services. Through this the hackers can do whatever they want such as data theft or eavesdropping [86]. Among different types of malware injections, the most common form is SQL injection [19]. The concept of SQL injection is to change the query structure. The hackers will use the improper validation of data to take advantage $[69,70]$. Usually their target is SQL servers or databases. Besides, hackers will try to inject a malicious code, especially to web server to bypass the login stage and gain access to the 
databases. They will try to modify database data, retrieve organizations' data and even take the control of the entire web server. The techniques or malicious scripts that hackers will use are JavaScript, HTML, VBScript, ActiveX and Flash [85].

\subsection{Wrapping Attack}

Wrapping attack which uses Extensible Mark-up Language (XML) signature element in order to weaken the web servers' validation requests [93]. When a user requests for a service, it is interacted using Simple Object Access Protocol (SOAP) and submitted in XML format. This type of attack usually occurs during the translation of SOAP messages in Transport Layer Service (TLS) layer between web server and valid user [41]. The message body will be duplicated and send to server as a valid user. The hacker will copy the user's account login details. During the login session, the hackers will inject a spurious element in the message structure. They will modify the original content with malicious code. After that, the message is sent to servers. The server will approve the message as the body is unchanged. As a result, the hackers will be able to access to the server resources to unauthorized access [79].

\subsection{Authentication Attack}

Authentication attack is also a type of attack that occurs in a cloud environment. [78] and [95] stated that authentication is always a weak point in web server and always become a target to attack especially the one with ineffective encryption system. Every service provider will use three types of authentication such as something a person knows, has, are [49]. During the authentication process, the hackers try to access the user's credential and confidential information. If they succeed, the hackers are able to access users' confidential data, organizations' sensitive information etc.

\subsection{Denial of Service (DoS) Attack}

Denial of Service (DoS), which also called as Distributed Denial of Service (DDoS) or flooding attack has become one of the most concern issue in cloud computing and a major trouble to the services availability. Although the network security experts have been putting efforts for decades to solve this attack, DoS attack continues to grow and have more impacts recently [92]. [49] and [89] highlighted the types of DoS attack such as smurf attack, SYN Flood attack, PING of Death attack, Tear Drop and IP Spoofing attack. The attackers can launch different types of DoS attack, including resource-focused (network, memory, CPU etc.) and application-focused (web applications, database services etc.) [92]. They make the services on cloud inaccessible, intolerably slow or unavailable, thus degrade the quality of services and the network connectivity [65]. One of the ways that usually attackers will do is to send large amount of data packets. The main purpose is to overload the servers' capacity and bandwidth and make the services unavailable [8]. According to [39], DoS attacks can occur at any layer in network. For example, DoS attack at network level to make the server unreachable, SYN Flood attack at the transport layer to get the server busy and send fake requests to the application layer to consume the servers' memory [53].

\subsection{Data Privacy}

In cloud computing, data will be accessed in unencrypted form by different organizations. According to [91], data privacy risks can be illustrated from different perspectives such as insufficient user control and regulatory compliance. Some organizations will upload files to cloud for sharing purposes. However, this would lead to confidentiality and data privacy issues such as protection of personal or organizations' business information. Sometimes, the location of data 
stored will lead to privacy obligations. Failure of security access rights across multiple domain will lead to data leakage. Besides the percentage of exposures and vulnerabilities will arise, thus insider user threats will be made [46]. Not much controls provided by providers on the data and information stored in the cloud. For example, in SaaS environment, [67] stated that the service providers are responsible for data storage which control and visibility is finite. There is an increase in threat of theft. Since all cloud processes are done by computers, the users do not know where their data stored and what have been done to it. The storage servers are distributed in different location around the world [26]. Sometimes it is difficult to guarantee that the data are compliance with the legislation since the cloud computing are all around the world and will have different legislations in different places. Thus placing data in the cloud may affect privacy and obligation [57].

\section{Suggested Solutions To OverCome Risks}

Cloud computing brings conveniences to the organizations, but there are some risks threatening organizations too. In order to provide a better quality of services, the providers have responsibilities to ensure that cloud environment is highly secured. Providers have to make enhancement on security to gain users' trust. There are some solutions to enhance the security of cloud.

\subsection{Data Stealing Solution}

Data stealing is usually widely occurred. The attackers will try to steal users' account credentials. To prevent this, a special and distinct number should be generated at login session [9]. Every time the session ends, the users are required to send an email about the usage and duration together with the unique number for the next login. Through this, the users will be more aware of the usage and unique number to be used for every login. For example, in Amazon EC2 cloud service, a unique number is used to verify the users [59]. For retail organizations, it requires the users to register as a user first before purchasing something. The information includes credit card details. [45] stated that it is necessary to enhance registration system to reduce the chance of customers' data stolen. This can be done by applying credit card fraud monitoring system. Security policy, rules and regulations can reduce the risks of improper use of cloud computational power.

\subsection{Malware Attack Solution}

In cloud computing, the users' requests are processed based on authorization and authentication and these will be done between web servers and web browsers. Hackers will try to inject harmful code to the cloud environment. To prevent this, cloud service providers need to store the information about the Operating System (OS) the users use during the first time registration. Since cloud computing is a fully independent OS platform, cross checking will be done before launching an instance on a cloud. This is to check whether the OS information stored on the cloud is matched with the instance requested from [40].

\subsection{Wrapping Attack Solution}

Wrapping attack can be prevented by enhancing the security between the communication with the web server and a web browser. This can be done by adding an extra bit which called reductant STAMP bit contains signature value to the SOAP message $[15,72]$. This type of bit is used to prevent the value being changed by the attackers. If there is any interfere during the communication, the STAMP bit will be toggled and new signature value will be produced in browser and is sent to the server. 


\subsection{Authentication Attack Solution}

Authentication is always a weak point, especially in a cloud environment. [82] and [95] highlighted the ways to enhance authentication on cloud. They said it is necessary to use a stronger authentication and ID management for both cloud providers and users. One of the ways is to use Key Management for both sides. Server logs should be used to record the access time. Besides, the account should be automatically locked after several unsuccessful login attempts.

\subsection{Denial of Service Attack Solution}

The solution to overcome this attack is still improving. One common way is to enhance the security of networks [62]. Several approaches such as filter-based, firewall-based and signature based can be used to eliminate the attacks [65, 73, and 79]. Filter-based approach can be used to detect a low rate of attacks like an increase and attack in traffic rate and network. Firewall-based approach is to use a firewall in order to enhance the strategy. It can be used to allow or deny protocol access. For example, if an attack is coming from an unusual IP address, the firewallbased approach will try to drop the unauthorized coming traffic. Signature-based approach is used to compare the signature database. In the network, the traffic is monitored with the signature pattern. If the signature does not match each other, it will block the attacks. [74] said the packets amount sent to the server by attackers is "multiplied by a factor that is similar to the number of hosts behind the router". They suggested that by disabling IP broadcast can reduce the chances of DoS attacks. Another way is applying the security patches. Operating System (OS) and applications can be the victims of DoS attack. To prevent from the attacks, the OS should have installed with the latest security patches. For example, when there is a SYN Flood attack, the servers should have software patches to detect and avoid it [49].

\section{Conclusion And Future Research}

Cloud computing has become one of the transformational technologies that is tremendously important to improve ways of doing business. It has been proved to be a valuable asset for organizations to stay competitive. Cloud computing has been defined from different perspectives by different experts and it is difficult to discern exactly how cloud computing is constituted. As discussed in this paper, cloud computing brings conveniences and benefits to the organizations such as business flexibility, cost reduction, automatic hardware and software upgrade, agility and scalability. The main benefit is it helps to reduce the unnecessary costs such as purchasing and maintaining hardware and software. Besides, the workers working in IT are reduced. However, like all other technologies, there are some issues with cloud computing. The biggest concern, issue is security, especially data stealing. More organizations will be willing to adopt cloud computing only if the issues are solved. Some solutions have been suggested to overcome these issues. The safety of cloud computing service should be placed at the front. Cloud service providers should provide regulatory compliances that the users may concern about. Through the compliances, it helps the users to be certified securely. Besides, security, policies should be provided with details regarding access control, risk management, system backup and recovery. Due to the time limitation, in the future, few case studies will be chosen and discussed on how organizations gained the benefits of cloud computing. Theoretical framework will be also used to discuss how organizations have applied framework. Different types of attacks always occur in a cloud environment, thus a strong theoretical concept and generalized architecture especially for security will be proposed. This is a crucial step required for the cloud service provider to handle the cyber-attack. 


\section{REFERENCES}

[1] Abdulaziz, A., 2012. Cloud Computing for Increased Business Value. International Journal of Business and Social Science, 3(1), pp. 234-239.

[2] Abhinay, B. A., Akshata, B. A. \& Karuna, C. G., 2013. Security Issues with Possible Solutions in Cloud Computing - A Survey. International Journal of Advanced Research in Computer Engineering \& Technology, 2(2), pp. 652-661.

[3] Adam, M. M. et al., 2014. Impact of Cloud Computing Adoption on Stock Price. Savannah, AISeL.

[4] Ahmed, Y., 2012. Exploring Cloud Computing Services and Applications. Journal of Emerging Trends in Computing and Information Sciences, 3(6), pp. 838-847.

[5] Akhila, R. \& Rakesh, R., 2015. Study and Analysis of Big Data in Cloud Computing. International Journal of Advance Research in Computer Science and Management Studies, 3(6), pp. 416-422.

[6] Ali, K. H., David, G. \& Ian, S., 2010. Cloud Migration: A Case Study of Migrating an Enterprise IT System to IaaS. Washington, IEEE.

[7] Amol, C. A., Vikram, D. S., Seema, H. P. \& Gopakumaran, T. T., 2015. Cloud Computing - A Market Perspective and Research Directions. International Journal of Information Technology and Computer Science, 10(1), pp. 42-53.

[8] Andrew, C., Mohammad, H. \& Omar, A., 2015. Defence for Distributed Denial of Service Attacks in Cloud Computing. Tunisia, Elsevier.

[9] Angadi, A. B., Angadi, A. B. \& Gull, K. C., 2013. Security Issues with Possible Solutions in Cloud Computing - A Survey. International Journal of Advanced Research in Computer Engineering \& Technology, 2(2), pp. 652-661.

[10] Angela, L. \& Chen, N. C., 2012. Cloud Computing as An Innovation: Perception, Attitude and Adoption. International Journal of Information Management, 32(6), pp. 533-540.

[11] Aniruddha, S. R. \& Chaudhari, D. N., 2013. Cloud Computing: Instructure as a Service. International Journal of Inventive Engineering and Sciences, 1(3), pp. 1-7.

[12] Ankeny, J., 2011. Heads in the Cloud. Entrepreneur, 39(10), pp. 50-51.

[13] Anthony, B. \& Syed, M. R., 2011. An Overview of the Security Concerns in Enterprise Cloud Computing. International Journal of Network Security \& Its Applications, 3(1), pp. 30-45.

[14] Apostu, A. et al., 2013. Study on Advantages and Disadvantges of Cloud Computing - The Advantages of Telemtry Applications in the Cloud. Morioka City, Iwate, Japan, World Scientific and Engineering Academy and Society.

[15] Apurva, S., Sanjay, S. \& Rahul, C., 2013. Security Aspects in Cloud Computing. International Journal of Engineering Trends and Technology, 6(3), pp. 118-120.

[16] Arnon, R. et al., 2010. Cloud Computing: A New Business Paradigm for Biomedical Information Sharing. Journal of Biomedical Informatics, 43(2), pp. 342-353.

[17] Assante, D., Castro, M., Hamburg, I. \& Martin, S., 2016. The Use of Cloud Computing in SMEs. Procedia Computer Science, 83(1), pp. 1207-1212.

[18] Astri, L. Y., 2015. A Study Literature of Critical Success Factors of Cloud Computing in Organizations. Procedia Computer Science, 59(1), pp. 188-194.

[19] Atul, S. C. \& Dhore, M. L., 2012. CIDT: Detection of Malicious Code Injection Attacks on Web Application. International Journal of Computer Applications, 52(2), pp. 19-26.

[20] Avram, M. G., 2014. Advantages and Challenges of Adopting Cloud Computing from Enterprise Perspective. Procedia Technology, 12(1), pp. 529-534.

[21] Buse, R. F., 2011. Why Use Cloud Computing?. Annals of University of Craiova - Economic Sciences Series, 3(39), pp. 228-231.

[22] Buyya, R. et al., 2010. Cloud Computing and Emerging IT Platforms: Vision, Hype and Reality for Delivering Computing as the 5th Utility. Future Generation Computer Systems, 25(1), pp. 599-616.

[23] Calheiros, R. et al., 2011. CloudSim: A Toolkit for Modeling and Simulation of Cloud Computing Environments and Evaluation of Resource Provisioning Algorithms. Software Practice and Experience, 41(1), pp. 23-50.

[24] Charu, A., 2011. Concepts, Challenges and Opportunities of Cloud Computing for Business Analyst. AKGEC International Journal of Technology, 2(2), pp. 25-30.

[25] Cheng, F. C. \& Lai, W. H., 2012. The Impact of Cloud Computing Technology on Legal Infrastructure within Internet-Focusing on the Protection of Information Privacy. International Workshop on Information and Electronics Engineering, 29(1), pp. 241-251. 
[26] Choubey, S. D. \& Namdeo, M. K., 2015. Study of Data Security and Privacy Preserving Solutions in Cloud Computing. Delhi, IEEE.

[27] Devi, T. \& Ganesan, R., 2015. Platform-as-a-Service (PaaS): Model and Security Issues. Telkomnika Indonesian Journal of Electrical Engineering, 15(1), pp. 151-161.

[28] Eric, K., 2011. The State of Small Business. Baylor Business Review, 30(1), pp. 4-9.

[29] Federico, E., 2011. The Economics of Cloud Computing. IUP Journal of Managerial Economics, 9(2), pp. 7-22.

[30] Gurmeet, S. \& Vineet, K. S., 2012. Impact and Challenges of Cloud Computing in Current Scenario. International Journal of Social Science \& Interdisciplinary Research, 1(10), pp. 131-144.

[31] Hamisu, A. A., 2015. Cloud Computing Security: An Investigation into the Security Issues and Challenges Associated with Cloud Computing, for both Data Storage and Virtual Applications. International Research Journal of Electronics \& Computer Engineering, 1(2), pp. 15-20.

[32] Hamoun, G., Bradley, S., Marin, L. \& Gabriel, I., 2012. Feedback-based Optimization of a Private Cloud. Future Generation Computer Systems, 28(1), pp. 104-111.

[33] Hashizume, K., Rosado, D. G., Medina, E. F. \& Fernandez, E. B., 2013. An Analysis of Security Issues for Cloud Computing. Journal of Internet Services and Applications, 4(5), pp. 1-13.

[34] Imran, A., 2014. An Overview of Service Models of Cloud Computing. International Journal of Multidisciplinary and Current Research, 2(4), pp. 779-783.

[35] Israr, H., 2013. Architecture Level Mapping of Cloud Computing with Grid Computing. International Journal of Engineering Sciences \& Emerging Technologies, 5(1), pp. 7-11.

[36] Jafar, S. et al., 2013. Identifying Benefits and Risks Associated with Utilizing Cloud Computing. The International Journal of Soft Computing and Software Engineering, 3(3), pp. 416-421.

[37] Jansen, M., 2011. What Does It Service Management Look Like in the Cloud?. Barcelona, World Scientific and Engineering Academy and Society.

[38] Johnston, K. A., Loot, M. \& Esterhuyse, M., 2016. The Business Value of Cloud Computing in South Africa. The African Journal of Information Systems, 8(2), pp. 1-20.

[39] Kashif, M. \& Sellapan, P., 2013. Secure Cloud Architecture. Advanced Computing: An International Journal, 4(1), pp. 9-22.

[40] Kazi, Z. \& Susan, V., 2010. Security Attacks and Solutions in Clouds. Berlin, ACM.

[41] Kouchaksaraei, H. R. \& Chefranov, A. G., 2013. Countering Wrapping Attack on XML Signature in SOAP Message for Cloud Computing. International Journal of Computer Science and Information Security, 11(9), pp. 1-6.

[42] Kulkarni, G., Sutar, R. \& Gambhir, J., 2012. Cloud Computing- Infrastructure as Service - Amazon EC2. International Journal of Engineering Research and Applications, 2(1), pp. 117-125.

[43] Kumar, M., 2014. Software as a Service for Efficient Cloud Computing. International Journal of Research in Engineering and Technology, 3(1), pp. 178-181.

[44] Lakshmi, D., 2014. Impact Study of Cloud Computing on Business Development. Operations Research and Applications: An International Journal, 1(1), pp. 1-7.

[45] Li, H. C., Po-Huei, L., Jiann Min, Y. \& Shiang Jiun, C., 2010. Analysis on Cloud-Based Security Vulnerabilities Assessment. s.1., IEEE.

[46] Mariana, C., AJ, M. V. d. \& Paula, K., 2011. Secure Cloud Computing Benefits, Risks and Controls. Johannesburg, IEEE.

[47] Martins, J. O., Sahandi, R. \& Tian, F., 2015. A Business Analysis of Cloud Computing: Data Security and Contract Lock-in Issues. Krakow, IEEE.

[48] Masudur, R. \& Wah, M. C., 2014. A Novel Cloud Computing Security Model to Detect and Prevent DoS and DDoS Attack. International Journal of Advanced Computer Science and Applications, 5(6), pp. 119-122.

[49] Masudur, R. \& Wah, M. C., 2014. Analysis of Cloud Computing Vulnerabilities. International Journal of Innovation and Scientific Research, 2(2), pp. 308-312.

[50] Mathew, N. \& Mahmoud, H., 2013. Dimensions of Security Threats in Cloud Computing: A Case Study. Review of Business Information Systems, 17(4), pp. 159-170.

[51] May, A.-R., Shaikha, A.-E., Sabika, B. \& Imtiaz, A., 2013. Cloud Computing Pricing Models: A Survey. International Journal of Grid and Distributed Computing, 6(5), pp. 93-106.

[52] Michael, A. et al., 2010. A View of Cloud Computing. Communication of the ACM, 53(4), pp. 50-58.

[53] Mohammed, A., 2014. Securing the Cloud: Threats, Attacks and Mitigation Techniques. Journal of Advanced Computer Science and Technology, 3(2), pp. 202-213.

[54] Nabil, S., 2010. Cloud Computing for Education: A New Dawn?. International Journal of Information Management, 30(2), pp. 109-116. 
[55] Nabil, S., 2010. Cloud Computing for Education: A New Dawn?. International Journal of Information Management, 30(1), pp. 109-116.

[56] Nazir, A. \& Jamshed, S., 2013. Cloud Computing: Challenges and Concerns for its Adoption in Indian SMEs. International Journal of Software and Web Sciences, 4(2), pp. 120-125.

[57] Nicholas, H., 2013. Compliance in the Ether: Cloud Computing, Data Security and Business Regulation. Journal of Business \& Technology Law, 8(1), pp. 255-273.

[58] Nikita, G. \& Toshi, S., 2014. Cloud Computing - SPI Framework, Deployment Models, Challenges. International Journal of Emerging Technology and Advanced Engineering, 4(1), pp. 19-25.

[59] Pankaj, S. \& Tripat, D. S., 2015. Data Security in Cloud. International Journal of Computer Science Engineering, 4(5), pp. 221-227.

[60] Parekh, D. \& Sridaran, R., 2013. An Analysis of Security Challenges in Cloud Computing. International Journal of Advanced Computer Science and Applications, 4(1), pp. 38-46.

[61] Piotr, P. \& Zbigniew, P., 2013. Cloud Computing - A Case Study for the New Ideal of the IS/IT Implementation. Zadar, ToKnowPress.

[62] Poonam, Y. \& Sujata, 2013. Security Issues in Cloud Computing Solution of DDoS and Introducing Two-Tier CAPTCHA. International Journal on Cloud Computing: Services and Architecture, 3(3), pp. 25-40.

[63] Pourqasem, J., Karimi, S. \& Edalatpanah, S. A., 2014. Comparison of Cloud and Grid Computing. American Journal of Software Engineering, 2(1), pp. 8-12.

[64] Rania, E.-G. F., 2014. A Literature Review on Cloud Computing Adoption Issues in Enterprises. IFIP Advances in Information and Communication Technology, 4(1), pp. 214-242.

[65] Rashmi, D. \& Kailas, D., 2015. Understanding DDoS Attack \& Its Effect in Cloud Environment. Procedia Computer Science, 49(1), pp. 202-210.

[66] Reza, S., Adel, A. \& Justice, O. M., 2013. Cloud Computing From SMEs Perspective: A Survey Based Investigation. Journal of Information Technology Management, 24(1), pp. 1-12.

[67] Richard, C. et al., 2010. Contolling Data in the Cloud: Outsourcing Computation Without Outsourcing Control. New York, ACM.

[68] Santosh, K. \& Goudar, R. H., 2012. Cloud Computing - Research Issues, Challenges, Architecture, Platforms and Applications: A Survey. International Journal of Future Computer and Communication, 1(4), pp. 356-360.

[69] Sara, Q. \& Kausar, F. K., 2012. Cloud Computing: Network/Security Threats and Countermeasures. Interdisciplinary Journal of Contemporary Research in Business, 3(9), pp. 1323-1329.

[70] Sayyed, M. S. S. \& Bahare, T. P., 2013. Study of SQL Injection Attacks and Countermeasures. International Journal of Computer and Communication Engineering, 2(5), pp. 539-542.

[71] Sean, M. et al., 2011. Cloud Computing - The Business Perspective. Decision Support Systems, 51(1), pp. 176-189.

[72] Shashi, C., Iti, R. \& Nitasha, H., 2013. Analyzing Security Solutions in Cloud Computing. International Journal of Computer Applications, 68(25), pp. 17-21.

[73] Shikha, S. et al., 2014. Cloud Computing Attacks: A Discussion with Solutions. Open Journal of Mobile Computing and Cloud Computing, 1(1), pp. 1-10.

[74] Shweta, T. et al., 2013. Hadoop Based Defense Solution to Handle Distributed Denial of Service (DDoS) Attacks. Journal of Information Security, 4(1), pp. 150-164.

[75] Singh, S. \& Jangwal, T., 2012. Cost Breakdown of Public Cloud Computing and Private Cloud Computing and Security Issues. International Journal of Computer Science \& Information Technology, 4(2), pp. 17-31.

[76] Smith, A., Bhogal, J. \& Sharma, M., 2014. Cloud Computing: Adoption Considerations for Business and Education. Barcelona, IEEE.

[77] Srinivas, A., Seetha, R. \& Venkatesh, L., 2013. A Study On Cloud Computing Disaster Recovery. International Journal of Innovative Research in Computer and Communication Engineering, 1(6), pp. 1380-1389.

[78] Subashini, S. \& Kavitha, V., 2011. A Survey on Security Issues in Service Delivery Models of Cloud Computing. Journal of Network and Computer Applications, 34(1), pp. 1-11.

[79] Subramaniam, T. \& Deepa, B., 2015. A Review Towards DDoS Prevention and Detection Methodology. International Journal of Computational Science and Information Technology, 3(1), pp. $1-9$.

[80] Subramaniam, T. K. \& Deepa, B., 2016. Security Attack Issues and Mitigation Techniques in Cloud Computing Environments. International Journal of UbiComp, 7(1), pp. 1-11. 
[81] Sumit, G., 2014. Public vs Private vs Hybrid vs Community - Cloud Computing: A Critical Review. International Journal of Computer Network and Information Security, 3(1), pp. 20-29.

[82] Sumitra, B., Pethuru, C. R. \& Misbahuddin, M., 2014. A Survey of Cloud Authentication Attacks and Solution Approaches. International Journal of Innovative Research in Computer and Communication Engineering, 2(10), pp. 6245-6253.

[83] Tarannum, N. \& Ahmed, N., 2013. Efficient and Reliable Hybrid Cloud Architecture for Big Database. International Journal on Cloud Computing Services and Architecture, 3(6), pp. 17-29.

[84] Ta-Tao, C., Kazuo, N. \& Thoma, T. C., 2015. An Exploratory Study of Expected Business Value of Cloud Computing. Issues in Information Systems, 16(4), pp. 37-47.

[85] Tejinder, S. M. \& Sanjay, J., 2015. Model to Prevent Websites From XSS Vulnerabilities. International Journal of Computer Science and Information Technologies, 6(2), pp. 1059-1067.

[86] Te-Shun, C., 2013. Security Threats on Cloud Computing Vulnerabilities. International Journal of Computer Science \& Information Technology, 5(3), pp. 79-88.

[87] Tharam, D., Chen, W. \& Elizabeth, C., 2010. Cloud Computing: Issues and Challenges. s.1., IEEE.

[88] Tiago, O., Manoj, T. \& Mariana, E., 2014. Assessing the Determinants of Cloud Computing Adoption: An Analysis of the Manufacturing and Services Sectors. Information \& Management, 51(5), pp. 497-510.

[89] Vidhya, V., 2014. A Review of DoS Attacks in Cloud Computing. IOSR Journal of Computer Engineering, 16(5), pp. 32-35.

[90] Vimal, D. B. \& Prabakaran, N., 2014. Challenges and Issues of Deployment on Cloud. International Journal of Innovative Research in Computer and Communication Engineering, 2(2), pp. 3095-3101.

[91] Waleed, A.-M. \& Li, C. L., 2016. User Privacy and Security in Cloud Computing. International Journal of Security and Its Applications, 10(2), pp. 341-352.

[92] Wang, B., Zheng, Y., Lou, W. J. \& Hou, T., 2014. DDoS Attack Protection in the Era of Cloud Computing and Software-Defined Networking. North Carolina, IEEE.

[93] Wen Juan, L. \& Ling Di, P., 2010. Trust Model to Enhance Security and Interoperability of Cloud Environment. Beijing, Springer.

[94] Won, K., Soo, D. K., Eunseok, L. \& Sungyoung, L., 2010. Adoption Issues for Cloud Computing. Kuala Lumpur, ACM.

[95] Young, G. M., Hyo, J. S. \& Young, H. B., 2012. Cloud Computing Security Issues and Access Control Solutions. Journal of Security Engineering, 9(2), pp. 135-141.

[96] Zhang, Q., Cheng, L. \& Boutaba, R., 2010. Cloud Computing: State-of-the-Art and Research Challenges. Journal of Internet Service Application, 1(7), pp. 7-18.

\section{Authors}

Colin Ting Si Xue was born in Sibu, Sarawak, Malaysia. He received the B.Sc. degree in Software Engineering with first class honors from Asia Pacific University of Technology and Innovation. Currently pursuing M.Sc. in Technology Management at Asia Pacific University of Technology and Innovation. He has published several journals papers in the area of change leadership, cloud computing and human resource management. His interested research areas are business management, change management, cloud computing, database, knowledge management and leadership.

Felicia Tiong Wee Xin was born in Kapit, Sarawak, Malaysia. She completed her foundation at First City University College (formerly called KBU) in Kuala Lumpur. Currently pursuing her Bachelo $r$ at International Medical University in Kuala Lumpur. Her interested research areas are pediatrics and informatics.
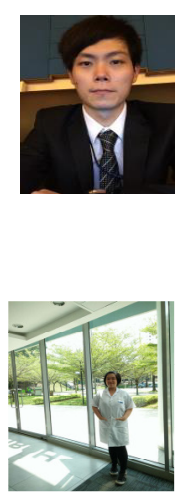